\title{
SSIs in Italy: Prevention and Surveillance during the Last Five Years
}

\author{
Carlo de Werra*, Sergio Aloia, Rosa di Micco, Roberto del Giudice, \\ Roberto Tramontano, Francesco Mangani, Ludovica Maria Esposito, \\ Gabriele di Filippo \\ General Surgery, Oncological, Geriatric, Endocrine and Advanced Technology Department, University of Naples \\ "Federico II", Naples, Italy \\ Email: ${ }^{*}$ dewerra@unina.it
}

Received 24 July 2015; accepted 16 August 2015; published 19 August 2015

Copyright (C) 2015 by authors and Scientific Research Publishing Inc.

This work is licensed under the Creative Commons Attribution International License (CC BY).

http://creativecommons.org/licenses/by/4.0/

(c) (†) Open Access

\section{Abstract}

Surgical site infections (SSIs) are recognized as a common surgical complication, occurring in about $2 \%-5 \%$ of all surgical procedures. For this reason, it is the second most common nosocomial infection, representing the $19.6 \%$ of all infections observed in hospitalized patients and $38 \%$ of those observed among surgical patients. Among SSIs prevention strategies, surveillance has been proved to be very incisive. The most recent surveillance study carried out at a national level in Italy is SNICh protocol (National Surveillance System of Surgical Site Infections), which analyses data received from 127 Italian hospitals, from the 2009 to 2011 and the entire 2013. The only application of a surveillance strategy, observing the recommended prophylaxis protocols, brought to a reduction of SSIs: their incidence has been shown to be comparable to European or American one. Furthermore, recent studies have brought strong evidence that the development of new devices, such as dressings impregnated with silver nanoparticles or triclosan-coated sutures, is strongly connected with the reduction of incidence of SSIs. In conclusion, if common preventive techniques were applied to all surgical procedures performed in the country, about 14,000 SSIs per year could be avoided with a possible savings after three years between 50 million and EUR 175 million euro.

\section{Keywords}

Surgical Site Infections (SSIs), General Surgery, Infections, Antibiotic Prophylaxis, Prevention, Surveillance

\footnotetext{
${ }^{*}$ Corresponding author.
}

How to cite this paper: de Werra, C., Aloia, S., di Micco, R., del Giudice, R., Tramontano, R., Mangani, F., Esposito, L.M. and di Filippo, G. (2015) SSIs in Italy: Prevention and Surveillance during the Last Five Years. Surgical Science, 6, 383-394. 


\section{Introduction}

Over the last 30 years the medicine is facing a new challenge: reducing of healthcare-associated infections (HAIs), which include surgical site infections (SSIs); this definition was introduced into medicine literature in 1992 to replace the previous "infection of the surgical wound" [1].

According to CDC and NHSN a SSI to be considered as such, must have some characteristics reported in Table 1 [2].

As can be seen SSIs are classified in incisional and organ-space infections; the former can be superficial if only skin and subcutaneous tissue of the incision are involved, or deep when they involve fascial and/or muscle layers.

Organ-space infections occur in any anatomical site that has been opened or manipulated during surgery.

Through this review we want to show how techniques of prevention, control and treatment of SSIs have changed over the years both in Italy and in Europe, stressing the importance of these infections on economic and clinical budget.

\section{Wound and Intervention Classification}

Before to talk about SSI epidemiology, it is necessary to introduce the classification of interventions and wounds, Table 2 [3].

This classification, only based on the grade of contamination during surgical procedure, has been improved from the National Nosocomial Infections Surveillance System (NNISS), adding two more important parameters:

- Clinical conditions (measured with ASA score).

- Surgical procedure duration (if $>3$ hours it is considered at a major rick of intraoperative contamination).

- The age of the patient [3].

In the case of long lasting surgical procedures, many guidelines suggest the use of an intra-operative dose, if the operation is still in course after a period equal to the doubles of the antibiotic half-life time. In order of the possible contaminating factor occurring during surgical intervention, it should be added a long list of risk factors for the infection of the surgical wound and for the post-operative infection usually connected to the patient and/or the hospital environment.

\section{Epidemiology}

The epidemiology of SSI is very difficult to establish because of their highly heterogeneous nature, moreover their incidence not only depend on type of surgical procedure but also on hospital, patient and surgeon.

In 2010, an estimated 16 million operative procedures were performed in acute care hospitals in the United States [4] and an American recent prevalence study found that SSIs were the most common healthcare-associated

Table 1. Main characteristic of each SSIs type according to CDC/NHSN [2].

\begin{tabular}{|c|c|c|c|}
\hline & $\begin{array}{c}\text { Superficial incisional } \\
\text { surgical site infection (SIP/SIS) }\end{array}$ & $\begin{array}{l}\text { Deep incisional surgical site } \\
\text { infection (DIP/DIS) }\end{array}$ & Organ/space surgical site infection \\
\hline $\begin{array}{c}\text { Time of } \\
\text { occurrence }\end{array}$ & $\begin{array}{l}\text { Within } 30 \text { days after the } \\
\text { operative procedure }\end{array}$ & $\begin{array}{c}\text { Within } 30 \text { days after the operative procedure } \\
\text { if no implant is left in place. } \\
\text { Within } 1 \text { year if implant is in place }\end{array}$ & $\begin{array}{l}\text { Within } 30 \text { days after the operative } \\
\text { procedure if no implant } \\
\text { is left in place. } \\
\text { Within } 1 \text { year if implant is in place }\end{array}$ \\
\hline $\begin{array}{l}\text { Anatomic area } \\
\text { involved }\end{array}$ & $\begin{array}{l}\text { Only skin and subcutaneous tissue } \\
\text { of the incision }\end{array}$ & $\begin{array}{c}\text { Deep soft tissues } \\
\text { (e.g. fascial and muscle layers) } \\
\text { of the incision }\end{array}$ & $\begin{array}{l}\text { Any part of the body that is } \\
\text { opened or manipulated during the } \\
\text { operative procedure } \\
\text { (excluding skin incision, fascia or } \\
\text { muscle layers) }\end{array}$ \\
\hline $\begin{array}{l}\text { Medical findings } \\
\text { of infection }\end{array}$ & $\begin{array}{l}\text { Purulent drainage from the } \\
\text { superficial incision } \\
\text { Organism isolated from an } \\
\text { aseptically obtained culture of fluid } \\
\text { or tissue from the superficial incision }\end{array}$ & $\begin{array}{l}\text { Purulent drainage from the superficial } \\
\text { incision (but not from the organ/space } \\
\text { component of the surgical site) } \\
\text { A deep incision spontaneously } \\
\text { dehisces or is deliberately opened by } \\
\text { surgeon and is culture-positive. }\end{array}$ & $\begin{array}{l}\text { Purulent drainage from a drain that } \\
\text { is placed through a stab wound } \\
\text { into the organ/space } \\
\text { Organism isolated from an } \\
\text { aseptically obtained culture of } \\
\text { fluid or tissue in the organ/space }\end{array}$ \\
\hline $\begin{array}{l}\text { Other signs and } \\
\text { symptoms } \\
\text { (at least 1) }\end{array}$ & $\begin{array}{l}\text { Pain or tenderness } \\
\text { Localized swelling } \\
\text { Redness or heat }\end{array}$ & $\begin{array}{c}\text { Fever }\left(>38^{\circ} \mathrm{C}\right) \\
\text { Localized pain or tenderness } \\
\text { Abscess or other evidence of infection } \\
\text { involving the deep incision }\end{array}$ & $\begin{array}{l}\text { Abscess or other evidence } \\
\text { of infection involving } \\
\text { the organ/space }\end{array}$ \\
\hline
\end{tabular}


Table 2. Classification of wounds and intervention according NNISS [3].

\begin{tabular}{|c|c|c|c|}
\hline & $\begin{array}{l}\text { Infection } \\
\text { percentage }\end{array}$ & Description & Antibiotic prophylaxis \\
\hline $\begin{array}{l}\text { Clean } \\
\text { (I) }\end{array}$ & $1.5 \%-4.2 \%$ & $\begin{array}{l}\text { Usually non traumatic. It presume that respiratory, } \\
\text { genitourinary and digestive tract are not } \\
\text { opened and the lack of technical mistakes. }\end{array}$ & $\begin{array}{l}\text { Not necessary, except for the } \\
\text { presence of risk factors and } \\
\text { comorbidities. }\end{array}$ \\
\hline $\begin{array}{l}\text { Clean-contaminated } \\
\text { (II) }\end{array}$ & $<10 \%$ & $\begin{array}{l}\text { Surgical procedures in which there is the opening of } \\
\text { respiratory, genitourinary and digestive tract in the } \\
\text { absence of an evident contamination, or the opening of } \\
\text { the oropharynx, genitor-urinary tract or biliary tract, } \\
\text { unless clearly infected. It is also included in this category } \\
\text { also any minor technical mistake. }\end{array}$ & Recommended. \\
\hline $\begin{array}{l}\text { Contaminated } \\
\text { (III) }\end{array}$ & $10 \%-20 \%$ & $\begin{array}{l}\text { Procedures following a frank contamination of } \\
\text { gastrointestinal tract or after the opening of } \\
\text { genitor-urinary or biliary tract with the } \\
\text { presence of urine or infected bile. } \\
\text { It is also included in this category also } \\
\text { any major technical mistake. }\end{array}$ & Necessary (wide spectrum). \\
\hline $\begin{array}{l}\text { Dirty } \\
\text { (IV) }\end{array}$ & $20 \%-40 \%$ & $\begin{array}{l}\text { Procedures with a frank contamination, clinical infection } \\
\text { in course, visceral perforation, purulent collections. }\end{array}$ & $\begin{array}{l}\text { The usage of antibiotics is necessary } \\
\text { for healing a pre-existing infections. }\end{array}$ \\
\hline
\end{tabular}

infection, accounting for 31\% of all HAIs among hospitalized patients [5]; the CDC found that there were about 157,500 surgical site infections associated with surgeries in 2011 [6].

In Europe, according to ECDC’s annual report, from 2011 to 2012 were reported 15000 HAIs, among which the most frequently were respiratory tract infections (23.5\%), surgical site infections (19.6\%), urinary tract infections (19.0\%), bloodstream infections (10.7\%), and gastro-intestinal infections (7.7\%) [7].

During last years, some European studies have pointed out the reduction of SSIs' incidence due to the increase of mini-invasive surgery procedures, indeed patients who underwent open cholecystectomy has a greater chance of SSIs compared to those who underwent laparoscopic cholecystectomy (4\% vs 1.1\%). Similarly, in patients with acute appendicitis the laparoscopic surgery granted a lower infection's rate in comparison to open surgery (2\% vs $8 \%$ ) [8]-[10].

These results are compatible with all features of mini-invasive surgery such as: small surgical site incisions, early patient discharge, reduction of post-surgical pain, preservation of immune system and the absence of a central venous catheter [8].

Overall, the incidence of SSI was significantly lower in laparoscopic $(0.5 \%)$ than in open $(1.8 \%)$ surgery (p < 0.01) [11]-[14].

\section{Clinical and Economic Burden}

The economic impact of SSIs on the health care system's budget is remarkable: for each patient with an SSI is frequently required a rehospitalisation or a hospitalisation in the intensive care unit (ICU) so they are known to be associated with increased length of stay (LOS) and additional cost.

An English study, performed at Derriford Hospital between April 2010 and March 2012, has analysed 14300 surgical procedures and 282 related SSIs (98\% - 34.8\%—were deep or organ-space and 184\% - 65.2\%—were superficial infections) [15].

The results show that the median additional LOS attributable to SSI for all surgical categories over the two-year period was 10 days (95\% Confidence Interval-CI: 7 - 13 days). In patients who developed a superficial or deep or organ space SSI postoperative LOS was significantly increased to 17 days (95\% CI: 13 - 18 days) and 24 days (95\% CI: 21 - 29 days) respectively compared with 5 days for those who did not develop an infection ( $<<0.01$ ); while the median additional postoperative LOS attributable to superficial SSIs and deep or organ space SSIs was 8 days (95\% CI: 7 - 11.5 days) and 15 days (95\% CI: 11 - 22 days) respectively [15].

Over this two-year period, a total of 4694 bed-days were lost by the hospital due SSIs (equivalent to 6.4 beds per day) and the median additional cost attributable to SSI for all surgical categories was £5,239 (95\% CI: 4.622 - 6.719), for a total of $£ 2,491,424[15]$. 
In France, during 2010, was estimated that 3\% of surgical procedures performed resulted in infection, for a total annual cost of $€ 57,892,715$ and, moreover, patients who experienced a SSI had a significantly increased mortality risk (from fourfold to fifteen-fold) and an increased length of hospital stay (threefold) [16] [17].

\section{Prevention Strategies}

Among all strategies to adopt for the prevention of SSI, surveillance and data reporting can effectively reduce the risk of infections.

The surveillance of nosocomial infection is conducted through the collection, the analysis and the interpretation of data, which follow the implementation of preventive actions and the evaluation of effectiveness of the measures applied.

It is necessary to understand that HAIs are not an indispensable result of healthcare assistance: a well-organized surveillance \& intervention system can substantially reduce the incidence of these problems and should be established in each hospital without considering economical, regulatory and organisational aspects [18] [19].

In order to prevent SSIs is important to follow a list of actions during all phases of hospitalization and surgery; recommendations of RCSI are listed and summarized in Table 3 [20].

The operating room represent a control point that, if carefully analysed, can greatly reduce the risk of infections; furthermore many recent studies showed that new single-use materials and more efficient sterilization methods are important features in SSIs' prevention.

Table 3. Key recommendations for practice in order to prevent surgical site infections [20].

\begin{tabular}{|c|c|c|}
\hline Type of prevention & Time of implementation & Grade of evidence \\
\hline $\begin{array}{l}\text { Avoid hair removal at the surgical site. If hair must be } \\
\text { removed use single-patient clippers and not razors. }\end{array}$ & Preoperative phase & $1 \mathrm{~A}^{2}$ \\
\hline $\begin{array}{l}\text { Wash the patient or ensure that has showered on } \\
\text { day of or day before surgery. }\end{array}$ & Preoperative phase & $1 \mathrm{~B}^{3}$ \\
\hline $\begin{array}{l}\text { Use the right drug, at the right time and for the } \\
\text { right duration for antibiotic prophylaxis }{ }^{1} \text {. }\end{array}$ & Preoperative phase & $1 \mathrm{~A}^{2}$ \\
\hline $\begin{array}{l}\text { Use } 2 \% \text { chlorhexidine gluconate in } 70 \% \text { isopropyl } \\
\text { alcohol solution for skin preparation. }\end{array}$ & Intraoperative phase & $1 \mathrm{~A}^{2}$ \\
\hline $\begin{array}{l}\text { Patient's body temperature should be maintained } \\
\text { above } 36^{\circ} \mathrm{C} \text { during the perioperative period. }\end{array}$ & Intraoperative phase & $1 \mathrm{~A}^{2}$ \\
\hline $\begin{array}{l}\text { Patient's haemoglobin saturation should be maintained } \\
\text { above 95\% (or as high as possible). }\end{array}$ & Intraoperative phase & $1 \mathrm{~B}^{3}$ \\
\hline $\begin{array}{l}\text { In diabetic patient the glucose level should be } \\
\text { kept at }<200 \mathrm{mg} / \mathrm{dl} \text { throughout the operation. }\end{array}$ & Intraoperative phase & $1 \mathrm{~B}^{3}$ \\
\hline $\begin{array}{l}\text { Give one additional antibiotic dose if the surgical } \\
\text { procedure lasts more than } 4 \text { hours or there is } \\
\text { major intra-operative blood loss ( }>1.5 \text { litres). }\end{array}$ & Intraoperative phase & $1 \mathrm{~A}^{2}$ \\
\hline $\begin{array}{l}\text { Cover the surgical site with a sterile wound dressing } \\
\text { before to remove drapes at the end of surgery. }\end{array}$ & Intraoperative phase & $1 \mathrm{~A}^{2}$ \\
\hline $\begin{array}{l}\text { Do not tamper with or remove the wound dressing } \\
\text { for } 48 \text { hours post-op, unless clinically indicated. }\end{array}$ & Postoperative phase & II \\
\hline $\begin{array}{l}\text { Use aseptic technique for surgical site inspection } \\
\text { and/or wound dressing changes. }\end{array}$ & Postoperative phase & $1 \mathrm{~A}^{2}$ \\
\hline $\begin{array}{l}\text { Hand hygiene is mandatory before and after every time } \\
\text { the wound is inspected or the dressing is changed. }\end{array}$ & Postoperative phase & $1 \mathrm{~B}^{3}$ \\
\hline
\end{tabular}

${ }^{1}$ Antibiotic prophylaxis should be prescribed according to local antimicrobial guidelines and it must be given at induction of anaesthesia, or otherwise within 60 minutes before skin incision, in single dose. "'Grade of evidence $1 \mathrm{~A}^{2}$ " means this statement is a strong recommendation in which benefits clearly outweigh risk and burdens and there is a consistent evidence from well performed randomized, controlled trials or overwhelming evidence of some other form. "“Grade of evidence 1B” means this statement is a strong recommendation in which benefits clearly outweigh risk and burdens but evidence was proofed by randomized, controlled trials with important limitations (inconsistent results, methodologic flaws, indirect or imprecise), or very strong evidence of some other research design. Further research (if performed) is likely to have an impact on our confidence in the estimate of benefit and risk and may change the estimate. 
In this regard some studies have pointed out that an alcohol-chlorhexidine solution, used for preoperative disinfection of the skin, is more effective in reducing SSIs than the "classic" povidone-iodine solution [21] [22].

Another key feature is the role of hand hygiene in HAI prevention: in fact healthcare workers' hand are the most common vehicle for the transmission of pathogens from patient to patient and within the environment. The use of posters, focus groups, hand hygiene observation and alcohol-based rub introduction have lead to a significant reduction in HAIs' incidence (4.1 vs 1.2; p < 0.009) [23] [24].

Even though during last years was not yet proofed the role of triclosan-coated sutures (Vycril ${ }^{\circledR}$ Plus) in prevention of surgical-site infection [25]-[27], a recent French meta-analysis has demonstrated that the use of these sutures reduced the incidence of SSIs after clean, clean-contaminated and contaminated surgery with a strong grade of evidence (level 1a) [28].

\section{First Italian Report: From 2009 to 2011}

The first multicentre Italian surveillance study is performed by our national healthcare system (SSN) and contains surveillance data collected from 355 surgical wards in 12 Italian regions.

Although data from different hospitals can be different due to factors such as techniques and patient's characteristics, benchmarking SSI incidence between surgical wards and over time may allow identification of areas for targeted intervention and may help to better allocate resources.

Were considered 83,127 operations from 2009 to 2011 but the final number of operations for the study was 60,460 because procedures involving implants of prosthetic material were not considered due to the very different length of post-intervention follow-up that is required (one-year vs one month); moreover for 54,240 of these (89.7\%) there was no missing information. Main characteristics of the operations recorded by this study were reported in Table 4 [29].

Along with the diagnosis of surgical site infections, made by doctors or nurses during the hospitalization or in follow-up (up to 30 days after discharge), were also collected other data in order to calculate the SSI risk index such as: wound classification, ASA score and duration of intervention [29].

Were reported 1628 SSIs (2.6\%) among which 544 were either deep incisional or organ/space (33\% of SSIs rate) and the over $90 \%$ of them were diagnosed by day 22 from discharge.

This first analysis of the Italian SSI surveillance system had two main results:

1) SSIs occurred at a lower rate for operations performed in hospitals that participate regularly to the surveillance;

2) the total number of surgical procedures surveyed doubled over the study period.

At the same time were confirmed some of the risk factors already known to be associated with an increased or reduced risk of SSIs, also for the Italian population: longer intervention duration, an ASA score of at least three and pre-surgery hospital stay of at least two days were found to be associated with an increased risk of SSI; on the other hand, laparoscopic procedures were associated with a reduction of SSIs rate [11]-[14] [29].

Despite these results were also pointed out some limitations to this study:

- Although all physicians used the same definition throughout the country, it is possible that the clinical diagnosis varied between hospitals and even between wards of the same facility.

- Low representativeness both of all surgical procedures in our national program and the entire national healthcare systems participated in the surveillance program, indeed only 12 Italian regions sent surveillance data.

- Finally, interventions including a prosthetic implant were excluded in order of the difference in follow-up that is needed in this kind of infection.

At the end, if common preventive techniques were applied to all surgical procedures performed in the country, about 14,000 SSIs per year could be avoided with a possible savings after three years between 50 million and 175 million euro [29].

\section{The Last Italian Surveillance Report: 2013}

The most recent multicentre Italian study about SSIs was performed by SNICh (National Surveillance System of Surgical Site Infections), and analysed data received from 127 Italian hospitals (indexed according to NHSH operative procedure categories); conducted throughout 2013, it considered 67,502 non-orthopaedic surgeries [30]. 
Table 4. Main characteristics of the operations recorded in the SNICh programme (2009-2011), [29].

\begin{tabular}{|c|c|c|}
\hline & Operations n (\%) & Infections n (rate per 100 procedures) \\
\hline \multicolumn{3}{|l|}{ Duration of operation } \\
\hline Under the 75th percentile & 48,438 (80\%) & $1108(2.3 \%)$ \\
\hline Over the 75th percentile & $12,022(20 \%)$ & $520(4.3 \%)$ \\
\hline \multicolumn{3}{|l|}{ ASA score } \\
\hline 1 & $18,085(30 \%)$ & $285(1.6 \%)$ \\
\hline 2 & $26,019(43 \%)$ & $712(2.7 \%)$ \\
\hline 3 & $9410(16 \%)$ & $422(4.5 \%)$ \\
\hline 4 & $1804(3 \%)$ & $116(6.4 \%)$ \\
\hline 5 & $152(0 \%)$ & $9(5.9 \%)$ \\
\hline Unknown & $4990(8 \%)$ & $84(1.7 \%)$ \\
\hline \multicolumn{3}{|l|}{ Wound class } \\
\hline $\mathrm{I}$-clean & 29,055 (49\%) & $478(1.6 \%)$ \\
\hline II—clean/contaminated & $23,844(40 \%)$ & $673(2.8 \%)$ \\
\hline III—contaminated & 4947 (8\%) & $318(6.4 \%)$ \\
\hline IV—dirty & $1488(3 \%)$ & $152(10.2 \%)$ \\
\hline \multicolumn{3}{|l|}{ Technique of operation } \\
\hline Classic & 46,911 (79\%) & $1414(3 \%)$ \\
\hline Videoscopic & $12,125(21 \%)$ & $211(1.7 \%)$ \\
\hline \multicolumn{3}{|l|}{ Hospital stay before operation } \\
\hline$<2$ day & $28,499(47 \%)$ & 485 (1.7\%) \\
\hline$\geq 2$ day & 31,917 (53\%) & $1141(3.6 \%)$ \\
\hline \multicolumn{3}{|l|}{ Sex } \\
\hline Male & 20,298 (34\%) & $668(1.7 \%)$ \\
\hline Female & $40,162(66 \%)$ & $960(2.4 \%)$ \\
\hline \multicolumn{3}{|l|}{ Age } \\
\hline $0-1$ & $399(1 \%)$ & 7 (1.8\%) \\
\hline $2-5$ & $470(1 \%)$ & $6(1.3 \%)$ \\
\hline $6-15$ & $955(2 \%)$ & $23(2.4 \%)$ \\
\hline $16-45$ & $21,778(36 \%)$ & $376(1.7 \%)$ \\
\hline $46-65$ & $16,262(27 \%)$ & $461(2.8 \%)$ \\
\hline $66-85$ & $18,533(31 \%)$ & $690(3.7 \%)$ \\
\hline$\geq 85$ & 1955 (3\%) & $65(3.3 \%)$ \\
\hline \multicolumn{3}{|l|}{ Urgent operation } \\
\hline No & 45,044 (75\%) & $1174(2.6 \%)$ \\
\hline Yes & $15,006(25 \%)$ & $452(3 \%)$ \\
\hline \multicolumn{3}{|l|}{ Operative procedure category } \\
\hline Caesarean section & $12,970(21 \%)$ & $222(1.7 \%)$ \\
\hline Cholecystectomy & $9653(16 \%)$ & $162(1.7 \%)$ \\
\hline Breast surgery & $8724(14 \%)$ & $156(1.8 \%)$ \\
\hline Colon surgery & $6130(10 \%)$ & $508(8.3 \%)$ \\
\hline Herniorrhaphy & $4172(7 \%)$ & $50(1.2 \%)$ \\
\hline Open reduction of fracture & $2365(4 \%)$ & $14(0.6 \%)$ \\
\hline Appendectomy & 1957 (3\%) & $51(2.6 \%)$ \\
\hline Prostatectomy & $1558(3 \%)$ & $49(3.1 \%)$ \\
\hline Rectal surgery & $1412(2 \%)$ & $126(8.9 \%)$ \\
\hline Laminectomy & $1407(2 \%)$ & $5(0.4 \%)$ \\
\hline Thoracic surgery & $1010(2 \%)$ & $11(1.1 \%)$ \\
\hline
\end{tabular}


Main objectives of this study were to estimate the frequency of surgical site infections in Italy and in our districts, moreover compare this data with those obtained by the ECDC and NHSN.

A surveillance protocol has defined which operative procedures must be monitored, how long should surveillance lasts, which information must be collected and many other variables of interest (how make diagnosis of surgical site infection, class and type of surgery to include, duration of surgery, ASA score, risk index, etc.) [31].

The follow-up after discharge could be ambulatory, telephone-based or through a self-issued form given to the patient before he left the hospital.

Data were collected on regional base and then integrated in a national database. Interventions were aggregated in surgical procedure categories and each one associated to a different risk of infection. Furthermore, has been considered features of each single patient and the risk at the base of each surgical intervention [31].

In order to correctly estimate the difference in the individual risk, has been used the Infection Risk Index (IRI), that assume values of risk from $\mathrm{M}$ to $0,1,2$, 3; Table 5 shows how to calculate this score [30] [31].

The analysed population was structured according to Table 6 [31].

During the considered period has been reported 1198 SSIs, equal to about 1.8 infections every 100 procedures, and among them the $45 \%$ has been diagnosed successively to the discharge [31].

Serious infections represent more than one third of the total: 22\% interest deep tissues, $14 \%$ organs and spaces. Superficial SSIs represent the $64 \%$ of the infections. Table 7 shows the percentage of SSIs for main surgical categories [31].

Regarding antibiotic prophylaxis, the collected data concern 23,547 intervention and in the $44 \%$ of them is not possible to state if it has been performed (but is also probable that in different cases the registration has been omitted). The using percentage is shown in Table 8 [31].

Comparing the Italian data with those of the ECDC and NHSN, we can firmly state that SSI incidence in Italy is comparable with the American and European one.

Results of this study pointed out that SSI incidence is not significantly increased, at least regarding the quality of the collected data. Some problems have arisen in the collection of not obligatory information, invalidating the use of IRI score (in the $40 \%$ of the intervention was not possible to use this method) [31].

Our national guidelines recommend the use of a I or II generation cephalosporin and suggest the use of glycopeptides only for MRSA colonized patients or for those centres with high SSI MRSA related incidence.

This study shows how the correct use of antibiotic represent in Italy a central point in the management of the surgical patient and a primary objective in the politics of each hospital (antimicrobial stewardship) [31].

SNICh program, despite the significant increase of the supervised interventions, is still affected by a low participation, and this is even more relevant considering the demonstrated lowering SSI incidence (around the 29\%) in the centres with a surveillance of at least two years [31].

\section{Antibiotic Prophylaxis and Future Prospects}

SSIs are a very actual and serious problem, for this reason the research is studying new methods to face them.

First of all, regarding the optimal duration of an antibiotic prophylaxis, was demonstrated the non inferiority of short-term prophylaxis compared with the long term one [32]; moreover there are no evidences of more effectiveness of antimicrobial therapy if prolonged further than 24 hours from the beginning of the procedure [2] [4].

Short-term antibiotic prophylaxis should be preferred to longer-course regimen because of:

\section{Table 5. Calculation of IRI score [30] [31].}

\begin{tabular}{cc}
\hline Considered factors & Point \\
\hline Intervention class: contaminated or dirty & +1 \\
ASA score $>2$ & +1 \\
${\text { Intervention duration }>75^{\circ} \text { percentile of distribution }}^{1}$ & +1 \\
\hline
\end{tabular}

${ }^{1} 75^{\circ}$ percentile of distribution of procedure duration in that specific category. NB: for the colon surgery and the laparoscopic cholecystectomy it is removed 1 point to the IRI score (if the result is -1 , category is $\mathrm{M}$ ). 
Table 6. Main characteristics of the operations recorded in the SNICh programme (2013), [31].

\begin{tabular}{|c|c|}
\hline Characteristic & Description \\
\hline Sex & (n. 67,502) \\
\hline Female & 39,990 (59\%) \\
\hline Male & $27,512(41 \%)$ \\
\hline Age & (n. 67,502) \\
\hline Median & 54 (IQR: 37 - 70) \\
\hline \multicolumn{2}{|l|}{ ASA score } \\
\hline 1 & 19,567 (29\%) \\
\hline 2 & $26,372(39 \%)$ \\
\hline 3 & $10,424(15 \%)$ \\
\hline 4 & $1325(2 \%)$ \\
\hline 5 & $88(0 \%)$ \\
\hline Not known & $9726(14 \%)$ \\
\hline Intervention class & (n. 67,502) \\
\hline I—clean & 31,925 (47\%) \\
\hline II—clean-contaminated & $24,011(36 \%)$ \\
\hline III—contaminated & 3393 (5\%) \\
\hline IV—dirty-infected & $1558(2 \%)$ \\
\hline Not known & $6615(10 \%)$ \\
\hline Intervention duration & (n. 65,552) \\
\hline Median & 60 (IQR: 35 - 110) \\
\hline Infection risk index & (n. 67,502) \\
\hline $0-1$ & $34,112(50 \%)$ \\
\hline $2-3$ & $3343(5 \%)$ \\
\hline N.D. & 30,047 (44\%) \\
\hline Pre-operative hospital stay (days) & (n. 67,502) \\
\hline Median & 1 (IQR: 1 - 2) \\
\hline Post-operative hospital stay (days) & (n. 56,430) \\
\hline Median & 4 (IQR: 2 - 7) \\
\hline Type of intervention & (n. 67,502) \\
\hline Elective & $52,224(77 \%)$ \\
\hline Urgent & $14,405(21 \%)$ \\
\hline Not known & $873(1 \%)$ \\
\hline Intervention technique & (n. 67,502) \\
\hline Classic & $51,054(76 \%)$ \\
\hline Not known & $910(1 \%)$ \\
\hline Videoscopic & $15,538(23 \%)$ \\
\hline Perioperative antibiotic prophylaxis & (n. 23,547) \\
\hline Not performed & $2,100(9 \%)$ \\
\hline Not known & $10,473(44 \%)$ \\
\hline Performed & $10,974(47 \%)$ \\
\hline
\end{tabular}


Table 7. Description of infections incidence analysed during the study (indexed according to NHSH categories) [31].

\begin{tabular}{ccc}
\hline Categories & Interventions n & Infections n (rate per 100 procedures) \\
\hline Appendectomy & 1837 & $39(2.1 \%)$ \\
Breast surgery & 5334 & $49(0.9 \%)$ \\
Cholecystectomy & 5505 & $77(1.3 \%)$ \\
Colon surgery & 3879 & $349(9.0 \%)$ \\
Caesarian section & 9475 & $166(1.7 \%)$ \\
Herniorrhaphy & 2919 & $43(1.4 \%)$ \\
Abdominal hysterectomy & 1027 & $15(1.4 \%)$ \\
Others & 16,555 & $83(0.5 \%)$ \\
Ovarian surgery & 1192 & $2(0.1 \%)$ \\
Prostatectomy & 1247 & $18(1.4 \%)$ \\
Rectal surgery & 776 & $54(7.0 \%)$ \\
Thoracic surgery & 1030 & $2(0.2 \%)$ \\
Thyroid/parathyroid surgery & 1479 & $18(1.2 \%)$ \\
Laparotomy & 991 & $31(3.1 \%)$ \\
\hline
\end{tabular}

Table 8. Molecule used in antibiotic prophylaxis [31].

\begin{tabular}{ccc}
\hline Active principle & Intervention & Percentage on intervention with indicated molecule (n. 9.177) \\
\hline Cefazolin & 3626 & $40 \%$ \\
Ampicillin and enzymatic inhibitors & 1512 & $16 \%$ \\
Metronidazole & 976 & $11 \%$ \\
Cefuroxime & 891 & $10 \%$ \\
Ceftriaxone & 804 & $9 \%$ \\
Others & 528 & $29 \%$ \\
\hline
\end{tabular}

- Reduction of hospitalization costs.

- Drug toxicity.

- Emergence of resistant pathogens.

In terms of rationalize the national health system costs, it's recommended the use of short-term antibiotic regimen, since its efficacy and safety for clean plastic surgeries and most clean-contaminated surgeries. On the other hand, trials on larger scale are needed to further confirm these findings [32].

Also technology is giving a great input in medical field, for instance the production of new device like dressings impregnated with silver nanoparticles has shown an anti-biofilm and cytotoxicity activity against $P$. aeruginosa, a bacteria isolated of chronic wounds from a hospital patient, without any damage on human cells [33].

The BaFO (Bone Area Fraction Occupancy) study, analysing the difference of SSIs incidence between standard abdominal wound edge protection with surgical dressings and coverage with a sterile circular polyethylene drape, has shown that this device not only prevent displacement of skin pathogens into the surgical site such as incisional drapes do, but also effectively protect the skin, subcutaneous tissue, fascia and muscle from spillage of abdominal content during the surgical procedure; moreover it prevents hypothermia which, as demonstrated in several studies, is associated with SSI insurgence [34] [35].

\section{Conclusion}

In conclusion as we have analysed not only technology and progress in the search for increasingly innovative 
new antibiotic molecules, but also above all knowledge and good practices, both on the part of doctors that nurses and students, are important factors to prevent SSIs [23] [36]-[42].

\section{References}

[1] Horan, T.C., Gaynes, R.P., Martone, W.J., et al. (1992) CDC Definitions of Nosocomial Surgical Site Infections, 1992: A Modification of CDC Definitions of Surgical Wound Infections. Infection Control \& Hospital Epidemiology, 13, 606-608. http://dx.doi.org/10.1017/S0195941700015241

[2] Horan, T.C., Andrus, M. and Dudeck, M.A. (2008) CDC/NHSN Surveillance Definition of Health Care-Associated Infection and Criteria for Specific Types of Infections in the Acute Care Setting. American Journal of Infection Control, 36, 309-332. http://dx.doi.org/10.1016/j.ajic.2008.03.002

[3] Sganga, G. (2014) Surgical Site Infections. Urologia, 81, 191-195. http://dx.doi.org/10.5301/uro.5000102

[4] CDC (2010) Data from the National Hospital Discharge Survey. http://www.cdc.gov/nchs/data/nhds/4procedures/2010pro_numberpercentage.pdf

[5] Magill, S.S., et al. (2012) Prevalence of Healthcare-Associated Infections in Acute Care Hospitals in Jacksonville, Florida. Infection Control \& Hospital Epidemiology, 33, 283-291. http://dx.doi.org/10.1086/664048

[6] Magill, S.S., et al. (2014) Multistate Point-Prevalence Survey of Health Care-Associated Infections. New England Journal of Medicine, 370, 1198-1208. http://dx.doi.org/10.1056/NEJMoa1306801

[7] European Centre for Disease prevention and Control (2013) Surveillance Report: Point Prevalence Survey of Healthcare-Associated Infections and Antimicrobial Use in European Hospitals 2011-2012. ECDC-Stockholm. http://ecdc.europa.eu/en/publications/Publications/healthcare-associated-infections-antimicrobial-use-PPS.pdf

[8] Boni, L., Benevento, A., Rovera, F., et al. (2006) Infective Complications in Laparoscopic Surgery. Surgical Infection (Larchmt), 7, 109-111. http://dx.doi.org/10.1089/sur.2006.7.s2-109

[9] Chen, L.F., Anderson, D.J., Hartwig, M.G., et al. (2008) Surgical Site Infections after Laparoscopic and Open Cholecystectomies in Community Hospitals. Infection Control \& Hospital Epidemiology, 29, 92-94. http://dx.doi.org/10.1086/524335

[10] Sauerland, S., Lefering, R. and Neugebauer, E.A. (2004) Laparoscopic versus Open Surgery for Suspected Appendicitis. Cochrane Database of Systematic Reviews, 4, CD001546. http://dx.doi.org/10.1002/14651858.cd001546.pub2

[11] Varela, J.E., Wilson, S.E. and Nguyen, N.T. (2010) Laparoscopic Surgery Significantly Reduces Surgical-Site Infections Compared with Open Surgery. Surgical Endoscopy, 24, 270-276. http://dx.doi.org/10.1007/s00464-009-0569-1

[12] Romy, S., Eisenring, M.C., Bettschart, V., Petignat, C., Francioli, P. and Troillet, N. (2008) Laparoscope Use and Surgical Site Infections in Digestive Surgery. Annals of Surgery, 247, 627-632. http://dx.doi.org/10.1097/SLA.0b013e3181638609

[13] Forbes, S.S., Eskicioglu, C., McLeod, R.S. and Okrainec, A. (2009) Meta-Analysis of Randomized Controlled Trials Comparing Open and Laparoscopic Ventral and Incisional Hernia Repair with Mesh. British Journal of Surgery, 96, 851-858. http://dx.doi.org/10.1002/bjs.6668

[14] Aimaq, R., Akopian, G. and Kaufman, H.S. (2011) Surgical Site Infection Rates in Laparoscopic versus Open Colorectal Surgery. The American Surgeon, 77, 1290-1294.

[15] Jenks, P.J., Laurent, M., McQuarry, S. and Watkins, R. (2014) Clinical and Economic Burden of Surgical Site Infection (SSI) and Predicted Financial Consequences of Elimination of SSI from an English Hospital. Journal of Hospital Infection, 86, 24-33. http://dx.doi.org/10.1016/j.jhin.2013.09.012

[16] Lamarsalle, L., Hunt, B., Schauf, M., Szwarcensztein, K. and Valentine, W.J. (2013) Evaluating the Clinical and Economic Burden of Healthcare-Associated Infections during Hospitalization for Surgery in France. Epidemiology and Infection, 141, 2473-2482. http://dx.doi.org/10.1017/S0950268813000253

[17] Roy, S., Patkar, A., Daskiran, M., Levine, R., Hinoul, P. and Nigam, S. (2014) Clinical and Economic Burden of Surgical Site Infection in Hysterectomy. Surgical Infections, 15, 266-273. http://dx.doi.org/10.1089/sur.2012.163

[18] Barclay, L. (2007) Improvements Needed in Infection Control, Survey Suggests. Nursing, 28-36.

[19] Pittet, D. (2005) Infection Control and Quality Health Care in the New Millennium. American Journal of Infection Control, 33, 258-267. http://dx.doi.org/10.1016/j.ajic.2004.11.004

[20] Owens, P., McHugh, S., Clarke-Moloney, M., Healy, D., Fitzpatrick, F., McCormick, P. and Kavanagh, E. (2015) Improving Surgical Site Infection Prevention Practices through a Multifaceted Educational Intervention. Irish Medical Journal, 108, 78-81.

[21] Charehbili, A., Swijnenburg, R.-J., van de Velde, C., van den Bremer, J. and van Gijn, W. (2014) A Retrospective 
Analysis of Surgical Site Infections after Chlorhexidine-Alcohol versus Iodine-Alcohol for Pre-Operative Antisepsis. Surgical Infections, 15, 310-313. http://dx.doi.org/10.1089/sur.2012.185

[22] Sidhwa, F. and Itani, K.M.F. (2015) Skin Preparation before Surgery: Opinion and Evidence. Surgical Infections, 16, 14-23. http://dx.doi.org/10.1089/sur.2015.010

[23] Allegranzi, B. and Pittet, D. (2009) Role of Hand Hygiene in Healthcare-Associate Infection Prevention. Journal of Hospital Infection, 73, 305-315. http://dx.doi.org/10.1016/j.jhin.2009.04.019

[24] Capretti, M.G., Sandri, F., Tridapalli, E., Galletti, S., Petracci, E. and Faldella, G. (2008) Impact of Standardized Hand Hygiene Program on the Incidence of Nosocomial Infection in Very Low Birth Weight Infants. American Journal of Infection Control, 36, 430-435. http://dx.doi.org/10.1016/j.ajic.2007.10.018

[25] Apisarnthanarak, A., Singh, N., Bandong, A.N. and Madriaga, G. (2015) Triclosan-Coated Sutures Reduce the Risk of Surgical Site Infections: A Systematic Review and Meta-Analysis. Infection Control \& Hospital Epidemiology, 36, 169-179. http://dx.doi.org/10.1017/ice.2014.22

[26] Jung, K.H., Oh, S.J., Choi, K.K., Kim, S.M., Choi, M.G., Lee, J.H., et al. (2015) Effect of Triclosan-Coated Sutures on Surgical Site Infection after Gastric Cancer Surgery via Midline Laparotomy. Annals of Surgical Treatment and Research, 87, 311-318. http://dx.doi.org/10.4174/astr.2014.87.6.311

[27] Wang, Z., Jiang, C.P., Cao, Y. and Ding, Y.T. (2013) Systematic Review and Meta-Analysis of Triclosan-Coated Sutures for the Prevention of Surgical-Site Infection. British Journal of Surgery, 100, 465-473. http://dx.doi.org/10.1002/bjs.9062

[28] Daoud, F.C., Edmiston, C.E. and Leaper, D. (2014) Meta-Analysis of Prevention of Surgical Site Infections Following Incision Closure with Triclosan-Coated Sutures: Robustness to New Evidence. Surgical Infections, 15, 165-181. http://dx.doi.org/10.1089/sur.2013.177

[29] Marchi, M., Pan, A., Gagliotti, C., Morsillo, F., Parenti, M., Resi, D. and Moro, M.L. (2014) The Italian National Surgical Site Infection Surveillance Programme and Its Positive Impact, 2009 to 2011. Eurosurveillance, 19, Article ID: 20815. http://www.eurosurveillance.org/ViewArticle.aspx?ArticleId=20815 http://dx.doi.org/10.2807/1560-7917.es2014.19.21.20815

[30] Grilli, E., Parenti, M., Pan, A. and Moro, M.L. (2014) Surgical Site Infections Surveillance in Italy. Orthopaedic Intervention Year 2012-Non Orthopaedic Intervention Year 2013. ASSR Emilia-Romagna.

http://assr.regione.emilia-romagna.it/it/servizi/pubblicazioni/rapporti-documenti/report-snich-2013/at_download/file

[31] National Center for Prevention and Control of Diseases (CMM) (2011) National Surveillance System of Surgical Site Infections (SNICh): Protocol. ASSR Emilia-Romagna, Bologna.

http://assr.regione.emilia-romagna.it/it/servizi/pubblicazioni/rapporti-documenti/protocollo-sistema-nazionale-di-sorve glianza-delle-infezioni-del-sito-chirurgico-snich-aggiornamento-dicembre-2011/at download/file

[32] Zhang, Y., Dong, J., Qiao, Y., He, J., Wang, T. and Ma, S. (2014) Efficacy and Safety Profile of Antibiotic Prophylaxis Usage in Clean and Clean-Contaminated Plastic and Reconstructive Surgery. Annals of Plastic Surgery, 72, 121-130. http://dx.doi.org/10.1097/01.SAP.0000440955.93769.8c

[33] Velázquez-Velázquez, J.L., Santos-Flores, A., Araujo-Meléndez, J., Sánchez-Sánchez, R., Velasquillo, C., González, C., Martínez-Castañon, G. and Martinez-Gutierrez, F. (2015) Anti-Biofilm and Cytotoxicity Activity of Impregnated Dressings with Silver Nanoparticles. Materials Science and Engineering: C, 49, 604-611. http://dx.doi.org/10.1016/j.msec.2014.12.084

[34] Mihaljevic, A.L., Michalski, C.W., Erkan, M., Reiser-Erkan, C., Jäger, C., Schuster, T., Schuhmacher, C., Kleeff, J. and Friess, H. (2012) Standard Abdominal Wound Edge Protection with Surgical Dressings vs Coverage with a Sterile Circular Polyethylene Drape for Prevention of Surgical Site Infections (BaFO): Study Protocol for a Randomized Controlled Trial. Trials, 13, 57. http://dx.doi.org/10.1186/1745-6215-13-57

[35] Mihaljevic, A.L., Schirren, R., Özer, M., Ottl, S., Grün, S., Michalski, C.W., et al. (2014) Multicenter Double-Blinded Randomized Controlled Trial of Standard Abdominal Wound Edge Protection with Surgical Dressings versus Coverage with a Sterile Circular Polyethylene Drape for Prevention of Surgical Site Infections. Annals of Surgery, 260, 730739. http://dx.doi.org/10.1097/SLA.0000000000000954

[36] Durando, P., Bassetti, M., Orengo, G., Crimi, P., Battistini, A., Bellina, D., et al. (2012) Adherence to International and National Recommendations for the Prevention of Surgical Site Infections in Italy: Results from an Observational Prospective Study in Elective Surgery. American Journal of Infection Control, 40, 969-972. http://dx.doi.org/10.1016/j.ajic.2011.11.016

[37] Napolitano, F., Izzo, M.T., Di Giuseppe, G. and Angelillo, I.F. (2013) Evaluation of the Appropriate Perioperative Antibiotic Prophylaxis in Italy. PLoS ONE, 8, e79532. http://dx.doi.org/10.1371/journal.pone.0079532

[38] de Werra, C., Donzelli, I., Tramontano, S., Perone, M. and Forestieri, P. (2005) Preoperative Control of Surgical Infections. Acta Biomedica, 76, S27-S28. 
[39] Tramontano, S., Ciccone, F., Donzelli, I., Perone, M. and de Werra, C. (2005) Postoperative Infections and the Importance of Mini-Invasive Surgery, of Surgical Technique and of Technologies in Prevention: Our Experience. Acts of the XVIII SPIGC National Congress. Minerva Chirurgica, 60, S28.

[40] de Werra, C., Perone, M., Di Micco, R., Orabona, G., Montella, E., Galloro, G. and Triassi, M. (2009) New Materials in the Prevention of Surgical Site Infections. Acts of the CXI SIC National Congress.

[41] de Werra, C., Schiavone, D., Di Micco, R. and Triassi, M. (2009) Surgical Site Infections in Italy. Infections in Medicine, 17, 205-218.

[42] Di Micco, R., Del Giudice, R., Cervotti, M., De Filippo, D., Di Costanzo, A., Pagnini, F. and de Werra, C. (2013) Surgical Site Infections Prophylaxis in Obese Patient: Ertapenem Efficacy in Vivo and in Vitro. Acts of the XI IBAT National Congress, 21. 